\title{
Changes of body immunity and inflammatory response in HIV/HCV co-infected patients
}

\author{
YUHONG DONG ${ }^{*}$, XIAOLI ZHI ${ }^{*}$ and GUO LEI \\ Infection Department, Qingdao No. 6 People's Hospital, Qingdao, Shandong 266000, P.R. China
}

Received April 19, 2018; Accepted October 25, 2018

DOI: $10.3892 /$ etm.2018.6938

\begin{abstract}
Changes of body immunity and inflammatory response in human immunodeficiency virus (HIV)/hepatitis $\mathrm{C}$ virus (HCV) co-infected patients were investigated. Eighty HIV/HCV infected patients admitted to Qingdao No. 6 People's Hospital from August 2015 to December 2017 were selected and divided into two groups according to whether they were complicated with HCV infection or not $(n=40$ per group). The changes of the related humoral immune indexes, the related cellular immune indexes, the related indexes of hepatic function, the related indexes of inflammatory response in the two groups were compared, and the correlations of high-sensitivity C-reactive protein (hs-CRP) level with alanine aminotransferase (ALT) level, immunoglobulin $\mathrm{G}(\mathrm{IgG})$ level and cluster of differentiation $4^{+}\left(\mathrm{CD}^{+}\right)$level in the observation group were analyzed. The levels of related humoral immune indexes [immunoglobulin $\mathrm{G}$ ( $\mathrm{IgG}), \operatorname{IgA}$ and $\operatorname{IgM}$ levels], the related cellular immune indexes $\left(\mathrm{CD}^{+}\right.$ and $\left.\mathrm{CD}^{+}\right)$in the observation group were lower than those in the control group $(\mathrm{P}<0.05)$, and the $\mathrm{CD}^{+} / \mathrm{CD}^{+}$ratio in the observation group was lower than that in the control group $(\mathrm{P}<0.05)$. The levels of indexes of hepatic function [ALT, aspartate aminotransferase (AST) and total bilirubin] in the observation group were significantly higher than those in the control group $(\mathrm{P}<0.05)$. The levels of hs-CRP, interleukin-1 (IL-1) and tumor necrosis factor- $\alpha$ (TNF- $\alpha)$ in the observation group were significantly higher than those in the control group $(\mathrm{P}<0.05)$. There were positive correlations of hs-CRP level with ALT level and IgG level in the observation group $(\mathrm{P}<0.05)$. There was a negative correlation between hs-CRP level and $\mathrm{CD}^{+}$level in the observation group $(\mathrm{P}<0.05)$. The humoral and cellular immune functions of the $\mathrm{HIV} / \mathrm{HCV}$
\end{abstract}

Correspondence to: Dr Guo Lei, Infection Department, Qingdao No. 6 People's Hospital, 9 Fushun Road, Qingdao, Shandong 266000, P.R. China

E-mail: leiqdd1@163.com

*Contributed equally

Key words: HIV infection, HCV infection, humoral immunity, cellular immunity, hepatic function, inflammatory response co-infected patients are significantly limited, their hepatic function is significantly impaired and the levels of inflammatory cytokines are markedly increased. The level of hs-CRP is positively correlated with hepatic function and humoral immune function and negatively correlated with cellular immune function.

\section{Introduction}

Human immunodeficiency virus (HIV) is classified as a retrovirus, and hepatitis $\mathrm{C}$ virus $(\mathrm{HCV})$ is a flavivirus, both of which are single-stranded RNA viruses and have a chronic process after infection in human body (1). At the same time, because the two types of viruses have the same three routes of infection, mainly blood, sex and mother-to-child vertical transmission, $\mathrm{HIV} / \mathrm{HCV}$ coinfection occurs easily in clinic (2). A study claimed (3) that the infection rate via blood transmission, especially in intravenous drug abusers and illegal paid blood donors, is the highest. The study has confirmed that, of every 1 million HIV-infected people in China, those co-infected with HCV account for 30-35\% (4). After $\mathrm{HCV}$ infection, the proportion of its development to cirrhosis and even hepatocellular carcinoma is extremely high. After $\mathrm{HCV}$ infection, it will cause similar immune activation mechanism in the body, leading to significant increases in extrahepatic complications and mortality rate in patients (5).

Previous studies have confirmed (6) that the main impact of HIV mono-infection is to reduce the cellular immune function, especially to significantly reduce the levels and function of $\mathrm{CD}^{+} \mathrm{T}$. The immune function of $\mathrm{HCV}$ infected patients is also affected to some extent, and the impact on hepatic function should not be neglected (7). After infection of both viruses, especially in the acute infection period, the body inflammatory response is affected at the same time. After $\mathrm{HCV}$ infection, immune cells will be activated (8) to promote the levels of inflammatory cytokines, thereby inducing hepatic fibrosis. HIV infection will directly lead to the activation of hepatic stellate cells, thus causing hepatic fibrosis (9). However, there has been no systematic study on the changes of immune function and the levels of inflammatory cytokines in $\mathrm{HIV} / \mathrm{HCV}$ co-infected patients. In this study, we mainly investigated the changes of immune function and the levels of inflammatory response cytokines in $\mathrm{HIV} / \mathrm{HCV}$ co-infected patients. 


\section{Materials and methods}

General materials. Eighty HIV/HCV infected patients admitted to Qingdao No. 6 People's Hospital (Qingdao, China) from August 2015 to December 2017 were selected. All 80 patients were positively diagnosed with HIV infection. Of these, 40 patients were diagnosed with $\mathrm{HIV} / \mathrm{HCV}$ co-infection. The patients were diagnosed by blood biochemical tests and qualitative analysis of radionuclides, and they were in accordance with the diagnostic criteria for HIV and HCV infections set by the Chinese Society of Infectious Diseases, Chinese Medical Association in 2010, and no anti-HCV or anti-HIV treatment was given to them before inclusion. Those with malignant neoplasms, acute infection, severe cardiopulmonary, hepatic and renal dysfunctions, mental illness, long-term alcohol abuse, HBV infection, cirrhosis, and those who were pregnant or breastfeeding were excluded. According to whether the patients were HIV infected or HIV/HCV co-infected, they were divided into two groups, each included 40 patients. The observation group consisted of 25 males and 15 females, aged $18-50$ years, with an average of $41.2 \pm 2.3$ years, whose confirmed duration of HIV infection was from 1 month to 3 years, with an average of $1.1 \pm 0.1$ years, and whose confirmed duration of $\mathrm{HCV}$ infection was from 1 month to 1 year, with an average of $0.8 \pm 0.1$ months. The control group consisted of 26 males and 14 females, aged 18-50 years, with an average of $41.3 \pm 2.4$ years, whose confirmed duration of HIV infection was from 1 month to 3 years, with an average of $1.2 \pm 0.1$ months. There were no statistically significant differences in general data, such as sex, age and HIV infection duration, between the two groups $(P>0.05)$. The study was approved by the Ethics Committee of Qingdao No. 6 People's Hospital and informed consents were signed by the patients or the guardians.

Methods. The changes of the related humoral immune indexes [immunoglobulin $\mathrm{G}(\operatorname{IgG}), \operatorname{Ig} \mathrm{A}$ and $\operatorname{IgM}$ levels], the related cellular immune indexes [cluster of differentiation $4^{+}\left(\mathrm{CD} 4^{+}\right)$, $\mathrm{CD}^{+}$and $\mathrm{CD}^{+} / \mathrm{CD}^{+}$ratio], the related indexes of hepatic function [alanine aminotransferase (ALT), aspartate aminotransferase (AST) and total bilirubin levels], the related indexes of inflammatory response [high-sensitivity C-reactive protein (hs-CRP), interleukin-1 (IL-1) and tumor necrosis factor- $\alpha(\mathrm{TNF}-\alpha)]$ in the two groups were compared, and the correlation of hs-CRP level with ALT level, and IgG level and $\mathrm{CD} 4^{+}$level in the observation group was analyzed.

Evaluation criteria. Immune function tests were divided into the test for humoral immunity and the test for cellular immunity. The main testing indexes of humoral immunity included $\operatorname{IgG}(23.6-9.6 \mathrm{mg} / \mathrm{l}), \operatorname{IgA}(3.14-4.66 \mathrm{mg} / \mathrm{l})$ and $\operatorname{IgM}(3.05-3.85 \mathrm{mg} / \mathrm{l})$. The main testing indexes of cellular immunity included $\mathrm{CD}^{+}, \mathrm{CD}^{+}$and $\mathrm{CD} 4^{+} / \mathrm{CD} 8^{+}$ ratio. The main testing indexes of inflammatory cytokines included hs-CRP $(<10 \mathrm{mg} / \mathrm{l})$, TNF- $\alpha(1-10 \mathrm{ng} / \mathrm{ml})$ and IL-1 (130-250 ng/ml). The main testing indexes of hepatic function included ALT (0-40 U/l), AST (0-40 U/l) and total bilirubin $(5.1-19.0 \mu \mathrm{mol} / \mathrm{l})$.

Statistical analysis. Statistical Product and Service Solutions (SPSS) 21.0 (IBM Corp., Armonk, NY, USA) software was
Table I. Comparison of the related humoral immune indexes between the two groups ( $\mathrm{mg} / \mathrm{l}$, mean \pm standard deviation).

\begin{tabular}{lccc}
\hline Items & $\operatorname{IgG}$ & $\operatorname{IgA}$ & $\operatorname{IgM}$ \\
\hline Observation group & $10.0 \pm 0.1$ & $2.6 \pm 0.1$ & $2.3 \pm 0.1$ \\
Control group & $25.5 \pm 0.2$ & $4.5 \pm 0.2$ & $3.5 \pm 0.2$ \\
t value & 438.406 & 53.740 & 33.941 \\
P-value & $<0.001$ & $<0.001$ & $<0.001$ \\
\hline
\end{tabular}

IgG, immunoglobulin G.

Table II. Comparison of the related cellular immune indexes between the two groups (mean \pm standard deviation).

\begin{tabular}{lccc}
\hline Items & $\mathrm{CD} 4^{+}$ & $\mathrm{CD}^{+}$ & $\mathrm{CD} 4^{+} / \mathrm{CD} 8^{+}$ \\
\hline Observation group & $29.0 \pm 0.3$ & $25.4 \pm 0.3$ & $1.62 \pm 0.1$ \\
Control group & $36.2 \pm 0.5$ & $31.6 \pm 0.4$ & $1.94 \pm 0.2$ \\
t value & 78.095 & 78.424 & 9.051 \\
P-value & $<0.001$ & $<0.001$ & $<0.001$ \\
\hline
\end{tabular}

$\mathrm{CD} 4^{+}$, cluster of differentiation $4^{+}$.

Table III. Comparison of the related indexes of hepatic function between the two groups (mean \pm standard deviation).

\begin{tabular}{lccc}
\hline & & & $\begin{array}{c}\text { Total } \\
\text { bilirubin } \\
(\mu \mathrm{mol} / \mathrm{l})\end{array}$ \\
\hline Items & ALT (U/l) & AST (U/l) & Observation group \\
Control group & $82.3 \pm 3.5$ & $73.6 \pm 3.8$ & $32.5 \pm 1.3$ \\
t value & $40.1 \pm 1.3$ & $35.9 \pm 1.1$ & $16.3 \pm 0.9$ \\
P-value & 71.484 & 60.272 & 64.800 \\
\hline
\end{tabular}

ALT, alanine aminotransferase; AST, aspartate aminotransferase.

used for data analysis. Measurement data are presented as mean \pm standard deviation, $t$-test was used for the comparison of the means between the groups, $\chi^{2}$ test was used for the comparison of the ratios between the groups, and the Spearman's correlation-coefficient method was used for correlation analysis. $\mathrm{P}<0.05$ was considered to indicate a statistically significant difference.

\section{Results}

Comparison of the related humoral immune indexes between the two groups. The levels of related humoral immune indexes (IgG, IgA and $\operatorname{IgM})$ in the observation group were significantly lower than those in the control group $(\mathrm{P}<0.05)$ (Table I).

Comparison of the related cellular immune indexes between the two groups. The levels of $\mathrm{CD} 4^{+}$and $\mathrm{CD} 8^{+}$in the observation 
Table IV. Comparison of the related indexes of inflammatory response between the two groups (mean \pm standard deviation).

\begin{tabular}{lccc}
\hline Items & hs-CRP $(\mathrm{mg} / \mathrm{l})$ & $\mathrm{IL}-1(\mathrm{ng} / \mathrm{ml})$ & $\begin{array}{c}\mathrm{TNF}-\alpha \\
(\mathrm{ng} / \mathrm{ml})\end{array}$ \\
\hline Observation group & $35.1 \pm 1.6$ & $268.1 \pm 19.6$ & $17.4 \pm 0.6$ \\
Control group & $7.9 \pm 0.5$ & $128.3 \pm 10.2$ & $8.5 \pm 0.3$ \\
t value & 102.623 & 40.016 & 83.910 \\
P-value & $<0.001$ & $<0.001$ & $<0.001$ \\
\hline
\end{tabular}

hs-CRP, high-sensitivity C-reactive protein; IL-1, interleukin-1; TNF- $\alpha$, tumor necrosis factor- $\alpha$.

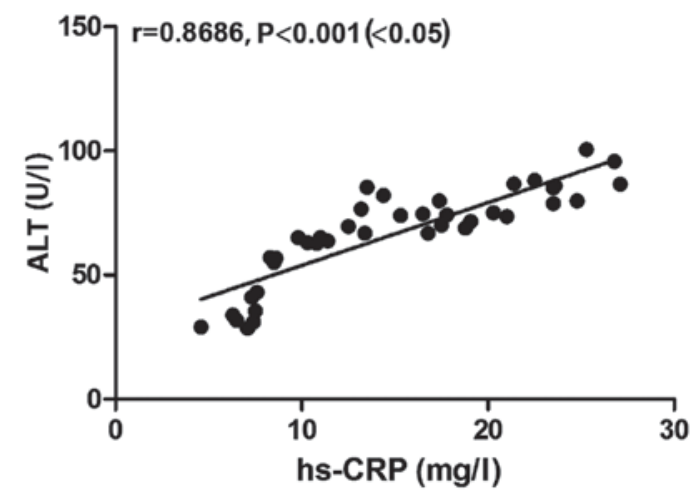

Figure 1. Correlation between hs-CRP level and ALT level in the observation group. There is a positive correlation between hs-CRP level and ALT level in the observation group $(\mathrm{r}=0.8686, \mathrm{P}<0.05)$. hs-CRP, high-sensitivity C-reactive protein; ALT, alanine aminotransferase.

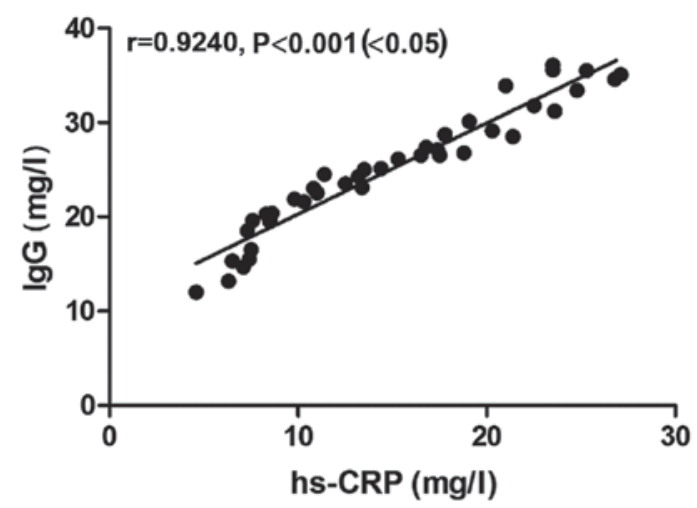

Figure 2. Correlation between hs-CRP level and IgG level in the observation group. There is a positive correlation between hs-CRP level and $\operatorname{IgG}$ level in the observation group $(\mathrm{r}=0.9240, \mathrm{P}<0.05)$. hs-CRP, high-sensitivity C-reactive protein; IgG, immunoglobulin G.

group were lower than those in the control group $(\mathrm{P}<0.05)$, and the $\mathrm{CD} 4^{+} / \mathrm{CD}^{+}$ratio in the observation group was lower than that in the control group $(\mathrm{P}<0.05)$ (Table II).

Comparison of the related indexes of hepatic function between the two groups. The levels of indexes of hepatic function (ALT, AST and total bilirubin) in the observation group were significantly higher than those in the control group $(\mathrm{P}<0.05)$ (Table III).

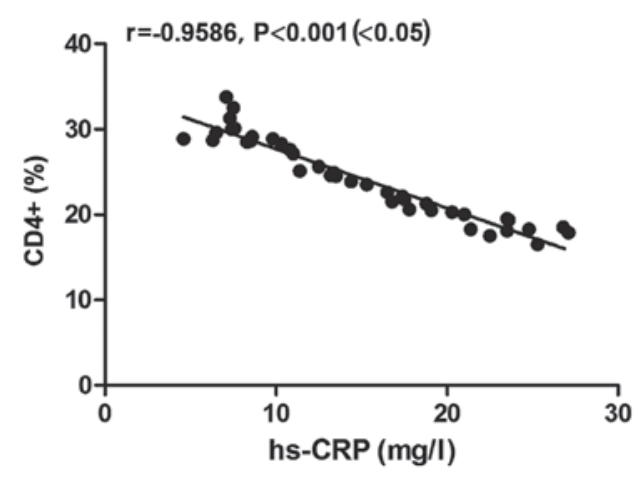

Figure 3.Correlation between hs-CRP level and CD4 ${ }^{+}$level in the observation group. There is a negative correlation between hs-CRP level and CD4 ${ }^{+}$ level in the observation group $(\mathrm{r}=-0.9586, \mathrm{P}<0.05)$. hs-CRP, high-sensitivity C-reactive protein; $\mathrm{CD}^{+}$, cluster of differentiation $4^{+}$.

Comparison of the related indexes of inflammatory response between the two groups. The levels of hs-CRP, IL-1 and TNF- $\alpha$ in the observation group were significantly higher than those in the control group $(\mathrm{P}<0.05)$ (Table IV).

Correlation between hs-CRP level and ALT level in the observation group. There was a positive correlation between hs-CRP level and ALT level in the observation group $(\mathrm{r}=0.8686, \mathrm{P}<0.05)$ (Fig. 1).

Correlation between hs-CRP level and IgG level in the observation group. There was a positive correlation between hs-CRP level and IgG level in the observation group ( $\mathrm{r}=0.9240$, $\mathrm{P}<0.05$ ) (Fig. 2).

Correlation between hs-CRP level and $C D 4^{+}$level in the observation group. There was a negative correlation between hs-CRP level and $\mathrm{CD}^{+}{ }^{+}$level in the observation group $(r=-0.9586, \mathrm{P}<0.05)($ Fig. 3).

\section{Discussion}

Previous studies have shown that HIV/HCV co-infection, compared with HIV mono-infection, causes more serious damage to immune function, and has a greater impact on hepatic function (10). hs-CRP is a commonly used clinical marker of inflammation, and the liver is the main place for the synthesis of hs-CRP. When the body's inflammatory response occurs after infection, the hs-CRP level will be significantly increased (11). Considering that HIV and HCV have the same routes of transmission and susceptible populations, the co-infection of HIV with HCV is common clinically (12). The HIV patients complicated with HCV infection, compared with HCV mono-infected patients, have more severe hepatic function impairment, which may develop into cirrhosis and even hepatoma sooner and in a higher proportion (13).

In this study, we compared the humoral and cellular immune functions of $\mathrm{HIV} / \mathrm{HCV}$ co-infected patients, and investigated the changes of hs-CRP, IL-1 and TNF- $\alpha$ in the patients. According to the study of the related humoral and cellular immune indexes, the levels of related humoral immune indexes (IgG, $\operatorname{Ig} \mathrm{A}$ and $\operatorname{IgM}$ ) in the observation group (HIV/HCV co-infected patients) were significantly lower than 
those of the control group, and the levels of $\mathrm{CD}^{+}$and $\mathrm{CD} 8^{+}$ were lower than those of the control group, and $\mathrm{CD} 4^{+} / \mathrm{CD}^{+}$ ratio was lower than that of the control group. It suggested that $\mathrm{HIV} / \mathrm{HCV}$ co-infection has a greater impact on immune function, and both humoral immunity and cellular immunity are significantly limited. In addition, through the comparative study on the related indexes of hepatic function in the two groups, it was found that the levels of indexes of hepatic function (ALT, AST and total bilirubin) in the observation group were significantly higher than those in the control group. This showed that HIV/HCV co-infected patients are impaired in hepatic function more severely than HIV mono-infected patients. At the same time, through the comparative study on the related indexes of inflammatory response in the two groups, it was found that the levels of hs-CRP, IL-1 and TNF- $\alpha$ in the observation group were significantly higher than those in the control group. It suggested that the inflammatory response of $\mathrm{HIV} / \mathrm{HCV}$ co-infected patients is more obvious, and the levels of the related inflammatory cytokines are significantly increased. Finally, the correlation study on hs-CRP level with ALT level, IgG level and $\mathrm{CD}^{+}{ }^{+}$level in the observation group suggested that the hs-CRP level was positively correlated with ALT level and IgG level, and negatively correlated with $\mathrm{CD}^{+}$ level in the observation group.

$\mathrm{HCV}$ infection will cause significant changes in immune function, and the hepatocellular inflammatory response caused by it will lead to hepatocyte fibrosis (14). HIV infection will directly cause the immune route activation of chemokine $\mathrm{CC}$ subclass receptors, which will cause the activation of hepatic stellate cells and lead to hepatic fibrosis (15). Among them, hs-CRP is the most common inflammatory marker in clinic. When the body has an inflammatory response, the hs-CRP level will be significantly increased, and the increased level of hs-CRP is positively correlated with inflammatory response and also positively correlated with hepatic function impairment (16). HCV infection causes the activation of immune cells, and leads to the increased secretion of hs-CRP through positive feedback. In HCV infection, especially in the acute infection period (17), the acute inflammatory response induced by hs-CRP will further aggravate hepatocellular injury and cause cirrhosis, even hepatoma (18). HIV infection will mainly inhibit the function of $\mathrm{CD} 4^{+} \mathrm{T}$ lymphocytes, and lead to immune tolerance and the lack of effective defensive ability of the body, then lead to a decrease in the ability of the body to recognize and eliminate $\mathrm{HCV}$ and an increase of the replication of $\mathrm{HCV}$, and this will further cause an increase in hs-CRP level, while a decrease in $\mathrm{CD}^{+}$level (19). $\mathrm{IgG}$ and IgM antibodies are non-protective antibodies, and $\mathrm{HCV}$ infection is mostly presented as the increase of IgG in the acute infection period, while the increase of $\operatorname{IgM}$ in the chronic infection period. HIV co-infection with HCV will cause further deterioration of the hepatic function impairment with a significant increase in $\mathrm{IgG}$, which is associated with an individualized ability to respond of the immune system, but after HIV co-infection, it will be significantly decreased (20).

In conclusion, the humoral and cellular immune functions of $\mathrm{HIV} / \mathrm{HCV}$ co-infected patients are significantly limited, their hepatic function is significantly impaired, and the levels of inflammatory cytokines are significantly increased. Among them, the hs-CRP level is positively correlated with hepatic function and humoral immune function, and negatively correlated with cellular immune function.

\section{Acknowledgements}

Not applicable

\section{Funding}

No funding was received.

\section{Availability of data and material}

All data generated or analyzed during this study are included in this published article. The datasets used and/or analyzed during the present study are available from the corresponding author on reasonable request.

\section{Authors' contributions}

YD and XZ drafted the manuscript, recorded and analyzed related humoral immune indexes and cellular immune indexes. GL contributed to the analysis of the hepatic function and of the indexes of the inflammatory cytokines. All authors read and approved the final study.

\section{Ethics approval and consent to participate}

The study was approved by the Ethics Committee of Qingdao No. 6 People's Hospital (Qingdao, China) and informed consents were signed by the patients or the guardians.

\section{Patient consent for publication}

Not applicable.

\section{Competing interests}

The authors declare that they have no competing interests

\section{References}

1. Mínguez C, García-Deltoro M, Flores J, Galindo MJ, Montero M, Reus S, Carmena J, Masiá M, Amador C and Ortega E; on the behalf of the COINFECOVA-2 study group: Interferon-free therapy for treating hepatitis $\mathrm{C}$ virus in difficult-to-treat HIV-coinfected patients. AIDS 32: 337-346, 2018.

2. Collins LF, Chan A, Zheng J, Chow SC, Wilder JM, Muir AJ and Naggie S: Direct-acting antivirals improve access to care and cure for patients with HIV and chronic HCV infection. Open Forum Infect Dis 5: of $264,2017$.

3. Ahmadinejad Z, Abdiliaei Z, Mohamadi R and Rezahosseini O: Treatment related hematologic changes in a population of Iranian patients with chronic hepatitis C infection from 2009 to 2014. Iran J Public Health 46: 1386-1394, 2017.

4. Tavitian-Exley I, Maheu-Giroux M, Platt L, Heimer R, Uusküla A, Levina O, Vickerman P and Boily MC: Differences in risk behaviours and HIV status between primary amphetamines and opioid injectors in Estonia and Russia. Int J Drug Policy 53: 96-105, 2018.

5. Kim YC, Ahn JY, Kim JM, Kim YJ, Park DW, Yoon YK, Song JY, Kim SW, Lee JS, Choi BY, et al: Human immunodeficiency virus (HIV) and hepatitis virus coinfection among HIV-infected Korean patients: The Korea HIV/AIDS cohort study. Infect Chemother 49: 268-274, 2017. 
6. Shmagel KV, Korolevskaya LB, Saidakova EV, Shmagel NG, Chereshnev VA, Margolis L, Anthony D and Lederman M: HCV coinfection of the HIV-infected patients with discordant CD4 T-cell response to antiretroviral therapy leads to intense systemic inflammation. Dokl Biol Sci 477: 244-247, 2017.

7. Suda G, Ogawa K, Morikawa K and Sakamoto N: Treatment of hepatitis C in special populations. J Gastroenterol 53: 591-605, 2018

8. Charre C, Cotte L, Kramer R, Miailhes P, Godinot M, Koffi J, Scholtès $C$ and Ramière $C$ : Hepatitis $C$ virus spread from HIV-positive to HIV-negative men who have sex with men. PLoS One 13: e0190340, 2018.

9. Ramamurthy M, Sankar S, Kannangai R, Nandagopal B and Sridharan G: Application of viromics: A new approach to the understanding of viral infections in humans. Virusdisease 28 349-359, 2017.

10. Benhammou V, Tubiana R, Matheron S, Sellier P, Mandelbrot L, Chenadec JL, Marel E, Khoshnood B and Warszawski J; ANRS CO1/CO11-EPF French Perinatal Cohort study group: HBV or $\mathrm{HCV}$ coinfection in HIV-1-infected pregnant women in France: Prevalence and pregnancy outcomes. J Acquir Immune Defic Syndr 77: 439-450, 2018.

11. Mohsenizadeh M, Mollaei HR and Ghaziizadeh $M$ : Seroepidemiological study of hepatitis B, C and HIV among blood donors in Kerman. Asian Pac J Cancer Prev 18: 3267-3272, 2017.

12. Köse Ş, Ödemiş I, Çelik D, Gireniz Tatar B, Akbulut I and Ciftdoğan DY: Hepatitis A, B, C and HIV seroprevalence among Şyrian refugee children admitted to outpatient clinics. Infez Med 25: 339-343, 2017.

13. Raj A, Mittal G and Bahadur H: Factors affecting the serological testing of cadaveric donor cornea. Indian J Ophthalmol 66 61-65, 2018.

14. Husseinzadeh H, Chiasakul T, Gimotty PA, Pukenas B, Wolf R, Kelty M, Chiang E, Fogarty PF and Cuker A: Prevalence of and risk factors for cerebral microbleeds among adult patients with haemophilia A or B. Haemophilia 24: 1271-277, 2018.

15. Najafi Fard S, Schietroma I, Corano Scheri G, Giustini N, Serafino S, Cavallari EN, Pinacchio C, De Girolamo G, Ceccarelli G, Scagnolari C, et al: Direct-acting antiviral therapy enhances total $\mathrm{CD}^{+}$and $\mathrm{CD} 8^{+} \mathrm{T}$-cells responses, but does not alter T-cells activation among HCV mono-infected, and HCV/HIV-1 co-infected patients. Clin Res Hepatol Gastroenterol 401: 302-362, 2017.
16. Sumbu BMM, Longo-Mbenza B, Ahuka-Mundeke S, Muwonga JM, Mvumbi-Lelo G, Maphana HM, Kayembe Nzongola-Nkasu D and Kalumbu FM: Association between the viruses of the acquired immunodeficiency syndrome and the hepatitis $\mathrm{C}$ virus among young blood donors in Kinshasa: Retrospective analysis of 10 years. Transfus Clin Biol 25: 26-34, 2018 (In French).

17. Notari S, Tempestilli M, Fabbri G, Libertone R, Antinori A, Ammassari A and Agrati C: UPLC-MS/MS method for the simultaneous quantification of sofosbuvir, sofosbuvir metabolite (GS-331007) and daclatasvir in plasma of HIV/HCV co-infected patients. J Chromatogr B Analyt Technol Biomed Life Sci 1073: 183-190, 2018.

18. Hua S, Vigano S, Tse S, Zhengyu O, Harrington S, Negron J, Garcia-Broncano P, Marchetti G, Genebat M, Leal M, et al: Pegylated IFN- $\alpha$-induced NK cell activation is associated with HIV-1 DNA decline in ART-treated HIV-1/HCV co-infected patients. Clin Infect Dis 20: 93-96, 2017.

19. D'Aleo F, Ceccarelli M, Venanzi Rullo E, Facciolà A, Di Rosa M, Pinzone MR, Condorelli F, Visalli G, Picerno I, Berretta M, et al: Hepatitis C-related hepatocellular carcinoma: Diagnostic and therapeutic management in HIV-patients. Eur Rev Med Pharmacol Sci 21: 5859-5867, 2017.

20. Rial-Crestelo D, Rodríguez-Cola M, González-Gasca FJ, Geijo-Martínez P, Belinchón-Moya O, Martínez-Alfaro E, Mateos-Rodríguez F, Barberá JR, Yzusqui M, Casallo S, et al: Effectiveness of direct-acting antiviral therapy in patients with a HCV/HIV coinfection. A multicenter cohort study. Rev Esp Enferm Dig 110: 35-43, 2018.

This work is licensed under a Creative Commons Attribution-NonCommercial-NoDerivatives 4.0 International (CC BY-NC-ND 4.0) License. 